\title{
Using results-based monitoring and evaluation to deliver results on key infrastructure projects in China
}

\author{
Yan Xue • J. Rodney Turner • Laurence Lecoeuvre • \\ Frank Anbari
}

Published online: 12 January 2013

(C) International Network of Business and Management 2013

\begin{abstract}
China has been investing heavily in infrastructure development to help fuel its economic growth. However, many projects fail to deliver the expected benefits because: (1) the expected returns were over-estimated, (2) key components of the new asset required to realize the full benefit have not been implemented and (3) the realization of benefits post-completion has not been effectively managed. Through this research, we aim to show that these problems can be addressed by adopting a resultsbased monitoring and evaluation system for benefits identification and realization throughout the project life cycle and for the creation of a project organization with clear responsibilities for project owners, sponsors and other stakeholders. We applied the results-based $M \& E$ system to analyze nine key infrastructure projects at various stages of their life cycle, including design, construction and operation. We formulated nine propositions and tested them through the nine case studies. We showed that project performance can be improved by adopting a results orientation throughout the project life cycle, and supporting this with a governance structure through which clear responsibilities are assigned for results delivery and benefits realization.
\end{abstract}

Y. Xue

Peking University, Beijing, People's Republic of China

e-mail: xueyan@ss.pku.edu.cn

J. R. Turner · L. Lecoeuvre

Skema Business School, LSMRC, Université Lille Nord de France,

Avenue Willy Brandt, 59777 Euralille, France

\section{J. R. Turner $(\bowtie)$}

Wildwood, Manor Close, East Horsley, Surrey KT24 6SA, UK

e-mail: rodneyturner@europrojex.co.uk; rodney.turner@skema.edu

F. Anbari

Goodwin College of Professional Studies, Drexel University, One Drexel Plaza,

3001 Market St., Suite 100, Philadelphia, PA 19104, USA

e-mail: anbari@drexel.edu 
Keywords Benefits realization - Life cycle - Project governance - Organization · Stakeholders

\section{Introduction}

Since the beginning of its economic reform in 1978, China's economy has grown at about $10 \%$ per year (Cheng 2007). To drive this growth and to improve the living standards of its citizens, China has invested heavily in infrastructure development. In China, gross capital formation represents $44 \%$ of gross domestic product (World Bank 2010). To achieve this growth, the expected benefits from these investments should be realized. However, some key development projects have failed to deliver the expected benefit (China National Audit Office 2004), and this requires the government to take money from other areas to pay for projects that fail to perform. Reasons for this shortfall include:

1. the expected returns were over-estimated

2. key components of the new asset required to realize the full benefit were not implemented

3. the realization of benefits post-completion was not effectively managed

China is not alone in intensive capital investment. Gross capital formation represents $22 \%$ of the global gross domestic product (World Bank 2010). This percentage tends to be higher in developing and transition economies than in developed economies. For instance, gross capital formation represents $17 \%$ of the economy in the UK, and $18 \%$ in the US, whereas in India it is $40 \%$, in the Russian Federation it is $26 \%$ and in Ireland it is $26 \%$ (World Bank 2010). Failure to achieve full benefits from key projects can have a significant global impact.

The World Bank and the Asian Development Bank (ADB) developed a resultsbased monitoring and evaluation (M\&E) system for key projects (Kusek and Rist 2004; Mackay 2006; Schiavo-Campo 2005) and the ADB sponsored a research project in China to see if the application of this system could help improve performance on key projects (Lockie et al. 2007). The results-based M\&E system monitors the project throughout the life cycle, from conception to benefits realization, to ensure that in the early stages the outputs, outcomes and desired benefits of the project are properly defined, and responsibility assigned for their definition and realization, and on project completion, the project output is commissioned, the outcome achieved, and the desired benefits realized.

This research was undertaken with the aim of seeing whether this system could be applied in China for developing a results-based M\&E system to improve the performance of key projects in China. The objectives of the research project are to answer the following two questions:

1. Can China realize the maximum benefit from key projects in the public sector by increasing results orientation and performance? Results orientation means to define clearly the desired outputs, outcomes and impact of a project, and ensure a suitable process is adopted to deliver those results. Performance means 
monitoring benefits realization during and after the project to ensure the desired outputs are commissioned, and produce the desired outcomes to realize the benefit.

2. Can a clear definition of the project organization, with the assignment of responsibility to project sponsors and owners, supported by sound public-sector governance, improve the benefits realization from key projects?

To answer these questions, nine case studies of key infrastructure projects in China were studied in detail. These nine projects were at various stages of the project life cycle including construction and post-commissioning operation and maintenance. In the next section, we describe the background to infrastructure projects in China and how they do not always achieve their desired outcomes. We then introduce the results-based M\&E System, and describe the nine case studies to show the contribution of using the system to the performance of the projects.

\section{Background}

The Chinese economic system

China operated a planned economy from 1949, the year the People's Republic of China (PRC) was established, to 1977, when China started its economical reform (Yao and Morgan 2008). The planned economy made important contributions by bringing China from a semi-feudal, semi-colonial, war ravaged nation to a worldclass industrialized nation. However, weaknesses in the system are clear. During that period, public money was mainly invested for political and military proposes, the national infrastructure was not well developed, and public services were poor. People's interests and needs were overlooked. The planned economy put the government as the sole decision maker and the only investor in projects. No feasibility studies were conducted and no monitoring and evaluation were carried out during and after project completion. The country's economy ran at low efficiency and public projects, which were the main contributor to economic development, were managed inefficiently.

Since 1978, China has undertaken economic reforms and made progress in economic and social development, safety and public project investment (Cheng 2007; Yao and Morgan 2008). The improvement of public-sector governance is a key part of the reforms (Tang and Lo 2009). Since 1978, government investment in projects has changed in scope, with more responsibility delegated to provincial and municipal governments. Substantial progress was made in project management, including the development of standards, regulations and methods. In the last 30 years, China's GDP has increased at an average rate of $10 \%$ per year (Cheng 2007). Consumption expenditure, investment and exports of goods and services are the three engines that drive China's GDP growth. Between 2000 and 2006, the average annual contribution of each to GDP was $45.6 \%$ by investment, $44.3 \%$ by consumption and $10.1 \%$ by exports (Xue 2009). It is clear that investment helps to fuel China's economic growth, both through the direct expenditure and by creating 
the infrastructure which supports the other two components of the economy (Huang and $\mathrm{Lu}$ 2008). It also improves the living standards of the population which also contributes to economic growth.

\section{Project performance}

Despite significant progress in investment in public projects, the current situation is still far from effective. Between 1998 and 2002, the central government provided funds to provinces, autonomous regions and municipalities for 1,965 projects to improve urban infrastructure and living standards. In 2003, the China National Audit Office conducted an audit of these projects (China National Audit Office 2004). They sampled 526 projects, including 230 sewage treatment projects, 83 waste disposal projects, 157 water supply projects, 33 gas supply projects and 23 central heating projects. The results showed attention had been paid by government at all levels, weak infrastructure was improved, the environment was better protected and people's living conditions were improved. These projects played a positive role in promoting sustainable economic and social developments. However, the audit identified many problems, some of which were serious, especially in terms of the delivery of expected results. Of the 526 audited projects, 320 were completed, but of those 32 were never operated and 18 were operated but only for a short time before being disbanded. Another 69 projects could not run at full capacities: 29 sewage treatment plants run at only $59 \%$ of design capacity, 6 solid waste treatment projects run at $56 \%$ of design capacity and 29 water supply projects run at $33 \%$ of design capacity. These projects outputs are not effectively used and outcomes were not reached. Many of these projects were completed on time, within budget, and to the designed specification, and so by conventional measures would be judged successful. However, they were far from successful in that they did not deliver the desired benefit. The main reasons for were:

1. The project outputs could not deliver the desired outcome. For example, two sewage treatment projects in Shanxi province did not consider the sewage pipe network in the design, financing and construction, so the completed sewage treatment plants were not connected to the waste water and have never operated.

2. Operating costs were not considered. For example, sewage treatment plants in Anhui and Liaoning Provinces have not operated fully because of a lack of operating funds.

3. The project feasibility study was not realistic. For example, a water supply system in Gansu Province has only run at $10 \%$ of the design capacity because that is the current water demand of the city it is supplying.

4. Poor quality of the output. For example, four solid waste treatment projects in Sichuan province have not operated effectively because of the poor quality of the plants.

The World Bank and the ADB have proposed a results-based M\&E system, supported by a clear project organization with defined responsibilities for the delivery of project results and sound public-sector governance, to address problems such as these. 


\section{Results-based monitoring and evaluation system}

The results-based M\&E system was developed in the first instance by the OECD (Binnendijk 2000), based on the logic model developed by the MW Kellogg Foundation (2004), Fig. 1, and was subsequently further developed by the World Bank for their investments (Kusek and Rist 2004). It suggests that to achieve results, it is necessary to do the planned work. The planned work consumes resources to undertake activities. It also shows three levels of results. The activities deliver outputs; in the case of a project this is a new asset. The operation of the output enables the investor to do new things, called the outcome. The ability to do new things leads to the ultimately desired impact. This can be the desired benefit but may also be higher order strategic objectives.

Lockie et al. (2007) and Xue (2009) have further developed this model for projects, Fig. 2 (Turner 2009; Turner et al. 2010). The project is initiated to achieve a strategic goal which identifies a need and a desired benefit. In the project itself, we consume resources to do work to deliver the new asset, the project's output. In the exploitation phase, we operate the asset to be able to do new things, the outcome. In the UK Government's methodology, Managing Successful Programmes, MSP (Office of Government Commerce 2007), the outcomes are called the capabilities delivered by the project. If it works well, the outcome will satisfy the need and provide the desired

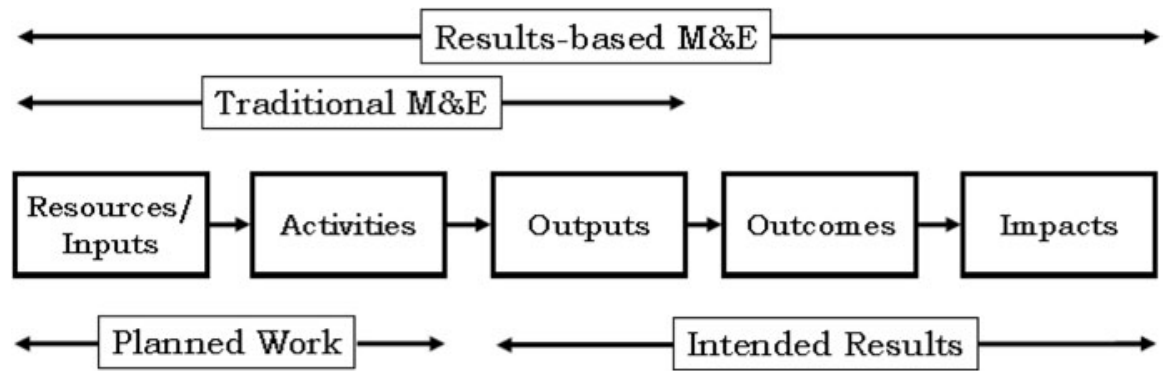

Fig. 1 Logic model (after MW Kellogg Foundation 2004)

Fig. 2 Results-based development, monitoring and evaluation for projects

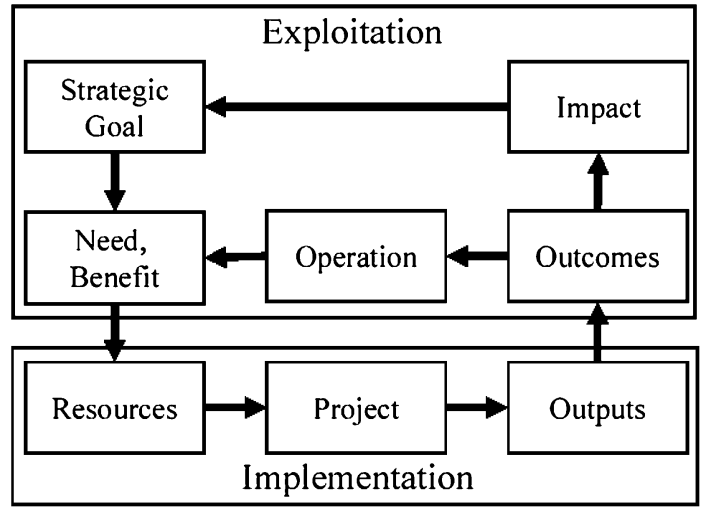


benefit. It will also lead to higher order results, the impact, which will deliver the strategic objective. For instance in the case of a waste water treatment plant, the asset is the plant and the pipework to gather the waste water. The outcome is the ability to treat waste water, which will provide benefit in the form of improved living conditions. The impact is that it may lead to improved public health.

Figures 1 and 2 also illustrate that results-based M\&E goes beyond traditional $M \& E$. In traditional M\&E, the aim of the project is to complete the work and deliver the new asset on time, cost and quality. Results-based M\&E asks whether the project achieved the desired outcome and impact. That is not only was the desired waste water treatment plant built on time, cost and quality, but it operated to treat the desired amount of waste water, the desired improvements in living standards were achieved and the desired improvements in public health were also achieved. The focus on and assignment of responsibility for these results must take place throughout the entire life cycle. In the feasibility stage, the investor must ensure the asset is designed to achieve the desired outcome, for instance the pipework is included in the design of the water treatment plant, operating costs are allowed for in the estimates, and demand for the product exists. The project is only judged successful if the outcome, impact and benefit are achieved, not if the work is completed on time, cost and quality.

Ownership must be assigned, so that throughout feasibility, design and construction this focus is maintained and the asset is designed and built to provide the desired outcome and impact. After commissioning, ownership is reassigned so identified people are responsible for ensuring the asset operates to achieve the desired outcome, and the outcome is used to achieve the desired benefit and impact. Through its PRINCE2 and MSP methodologies, the UK's Office of Government Commerce $(2007,2009)$ has developed a model of project organization, Fig. 3, with responsibilities defined for identifying and delivering results:

- The project manager is responsible for the project's output

- The project sponsor is responsible for the project's outcome

- The senior responsible owner is responsible for the project's impact.

On public-sector projects, people fulfilling these roles may come from different government departments. For instance on a water treatment plant, the project manager may come from the public works department, the sponsor from the water department and the senior responsible owner from the public health department. The project organization should facilitate their interaction by enabling them to communicate horizontally between departments.

However, for this to work effectively requires the good governance of publicsector projects.

\section{Governance of public-sector projects}

In recent years, there has been increasing concern about good governance in the public sector (Aberbach and Christensen 2003; Howard and Seth-Purdie 2005; 


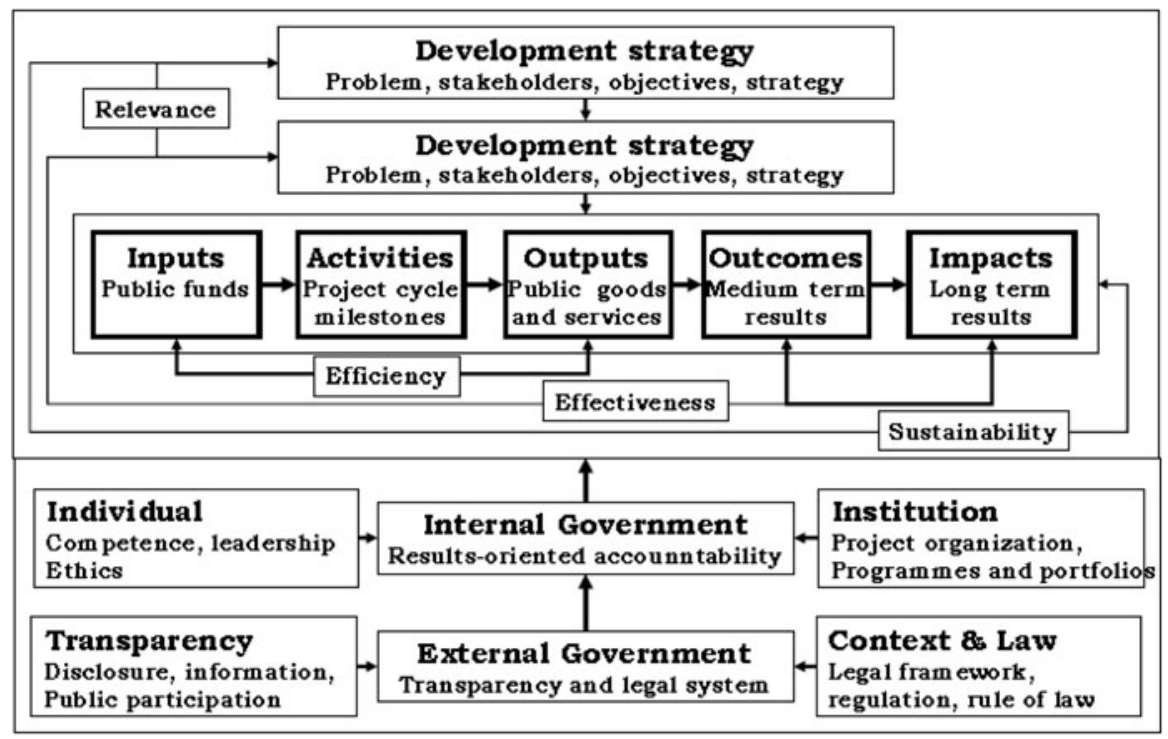

Fig. 3 Public-sector project management and results framework (after Xue 2009)

Bourgon 2009; Van Wie Davis 2009). In the past, good public-sector governance was considered mainly as a means of combating corruption. However, recent research has given a greater understanding of its benefits. In particular, public sectors that are more transparent and accountable are likely to be more effective and efficient at implementing and developing policy, delivering public services and goods and encouraging public participation in government (Cameron 2004). It is recognized that poor governance is reflected in inadequate service delivery, unfavourable policy environments, inappropriate allocation of public resources and corruption, all of which have a disproportionate impact on the poor (Asian Development Bank 2000; World Bank 2008). Furthermore, good governance practices in the public sector strengthen government systems. The public and businesses seek assurance that resources they contribute through taxation are used effectively and appropriately. While there is by now a strong consensus among both academics and policymakers that good governance provides the fundamental basis for economic development (Asian Development Bank 2000; World Bank 2008; Kulshreshta 2008), there is as yet no consensus about a definition of governance or good governance (Kaufmann et al. 2007; Asian Development Bank 2006). To enhance the quality of public governance, various authors and organizations have produced an array of definitions. We review four.

\section{World Bank}

The World Bank's Worldwide Governance Indicators (WGI) research project (Kaufmann et al. 2007; Kulshreshta 2008) defined public-sector governance as the traditions and institutions by which authority in a country is exercised. This includes: 
- the process by which governments are selected, monitored and replaced;

- the capacity of the government to effectively formulate and implement sound policies and

- the respect of citizens and the state for the institutions that govern economic and social interactions among them.

Based on this definition, they identified six elements of good governance:

1. Voice and accountability: measuring perceptions of the extent to which a country's citizens are able to participate in selecting their government, as well as freedom of expression, freedom of association and a free media.

2. Political stability and the absence of violence: measuring perceptions of the likelihood the government will be destabilized or overthrown by unconstitutional or violent means.

3. Government effectiveness: measuring perceptions of the quality of public services and its degree of independence from political pressures, the quality of policy formulation and implementation and the government's commitment to such policies.

4. Regulatory quality: measuring perceptions of the ability of government to formulate and implement sound policies and regulations that promote private sector development.

5. Rule of law: measuring perceptions of the extent to which agents have confidence in and abide by the rules of society, and in particular the quality of contract enforcement, property rights, the police and the courts, as well as the likelihood of crime and violence.

6. Control of corruption: measuring perceptions of the extent to which public power is exercised for private gain, and 'capture' of the state by elites and private interests.

\section{Asian Development Bank}

ADB defined governance as (Asian Development Bank 2000):

...the management of the development process involving both the public and private sectors. It encompasses the functioning and capability of the public sector, as well as the rules and institutions that create the framework for the conduct of both public and private business.

It later suggested that 'capacity development' is the process whereby people, organizations and society as a whole unleash, strengthen, create, adapt and maintain capacity over time (Asian Development Bank 2006). ADB regards good governance as synonymous with sound development management. It identifies four basic elements of good governance:

1. Accountability: public officials must be accountable or answerable for their actions and responsive to the entity from which their authority is derived.

2. Participation: the involvement of citizens in the development process. ADB promotes participation in governments by: 
- encouraging the participation of project beneficiaries and affected groups

- improving the interface between the public and the private sectors

- empowering local government by letting them take ownership of projects

- working with non-government organizations (NGOs) to mobilize project beneficiaries.

3. Predictability: the legal environment must be conducive to development. Predictability is about fair and consistent application of laws and implementation of government policies.

4. Transparency: the availability of information to the general public and clarity about government rules, regulations and decisions.

\section{United Nations, UN}

The UN defined governance simply as (Sheng 2008):

the process of decision making and the process by which decisions are implemented (or not implemented)

and suggests there are eight major characteristics of good governance:

1. Participation: this is cornerstone of good governance. Participation could be either direct or through legitimate intermediate institutions or representatives. Participation needs to be informed and organized.

2. Rule of law: good governance requires fair laws that are enforced impartially. It also requires protection of human rights, particularly for minorities. Impartial enforcement of laws requires an independent judiciary and an impartial and incorruptible police force.

3. Transparency: decisions taken and their enforcement are done in a manner that follows rules and regulations. Information is freely available and directly accessible to those who will be affected by such decisions and their enforcement. Adequate information is provided and is easily understandable.

4. Responsiveness: institutions and processes try to serve all stakeholders within a reasonable timeframe.

5. Consensus oriented: different interests in society reach a broad consensus on what is in the best interest of the community. There is a broad and long-term perspective on what is needed for sustainable development and how to achieve that. This can only result from an understanding of the historical, cultural and social contexts of a given society.

6. Equity and inclusiveness: a society's well-being depends on ensuring its members feel they have a stake in it and do not feel excluded. This requires all groups, but particularly the most vulnerable, have opportunities to improve or maintain their well-being.

7. Effectiveness and efficiency: processes and institutions produce results that meet the needs of society while making the best use of resources. Efficiency also covers the sustainable use of natural resources and the protection of the environment. 
8. Accountability: this is a key requirement of good governance. Not only governmental institutions but also the private sector and civil society organizations must be accountable to the public. Accountability cannot be enforced without transparency and the rule of law.

\section{The Australian Government}

The Australian Government defines the public-sector governance as (Barrett 2003; Australian National Audit Office 2003):

...the set of responsibilities and practices, policies and procedures, exercised by an agency's executive, to provide strategic direction, ensure objectives are achieved, manage risks and use resources responsibly and with accountability.

Good governance structures and forms can support sound performance but they do not guarantee it. Behaviours consistent with good governance increase the probability of positive and sustainable outcomes. The Australian National Audit Office identifies six principles for good public-sector governance (Barrett 2003; Australian National Audit Office 2003):

1. Accountability: being answerable for decisions and having meaningful mechanisms in place to ensure the agency adheres to all applicable standards

2. Transparency/openness: having clear roles and responsibilities and clear procedures for making decisions and exercising power

3. Integrity: acting impartially, ethically and in the interests of the agency, and not misusing information acquired through a position of trust

4. Stewardship: using every opportunity to enhance the value of the public assets and institutions that have been entrusted to care

5. Efficiency: ensuring the best use of resources to further the aims of the organization, with a commitment to evidence-based strategies for improvement

6. Leadership: achieving commitment to good governance through leadership.

The first three elements relate to personal qualities of those in the organization. The other three are mainly a product of strategies, systems, policies and processes (Barrett 2003).

\section{Combined model}

Xue (2009) combined these four models of good governance in the public sector to define seven principles, Table 1:

1. Integrity: acting impartially, ethically and in the interests of the agency, and not misusing information acquired through a position of trust

2. Stewardship: using every opportunity to enhance the value of the public assets and institutions that have been entrusted to care

3. Leadership: achieving a commitment to good governance through leadership

4. Efficiency: ensuring the best use of resources to further the aims of the organization, with a commitment to evidence-based strategies for improvement 
Table 1 Principles of good public-sector governance

\begin{tabular}{lllll}
\hline Combined & World Bank & ADB & UN & $\begin{array}{c}\text { Australian National } \\
\text { Audit Office }\end{array}$ \\
\hline $\begin{array}{l}\text { Internal-individual } \\
\text { Integrity }\end{array}$ & Absence of corruption & & \\
$\begin{array}{l}\text { Stewardship } \\
\text { Leadership }\end{array}$ & & & Integrity \\
Internal-public bodies & & & Stewardship \\
Efficiency & Effectiveness & & Leadership \\
Accountability & Accountability & Accountability & Accountability & Accountability \\
& & & Responsiveness & \\
External & & & Efficiency \\
Transparency & Regulation & Transparency & Transparency & Transparency \\
Rule of law & Rule of law & Participation & Participation & \\
& Political stability & Predictability & Rule of law & \\
& & Equity & \\
& & Consensus & \\
\hline
\end{tabular}

5. Accountability: being answerable for decisions and having meaningful mechanisms in place to ensure the agency adheres to all applicable standards

6. Transparency/openness: having clear roles and responsibilities and clear procedures for making decisions and exercising power

7. Rule of law: the extent to which agents have confidence in and abide by the rules of society, and in particular the quality of contract enforcement, property rights.

The first three reflect the responsibility of individuals within the public sector, and the fourth and fifth reflect the responsibility of public-sector bodies. Together they comprise the accountability of individuals and institutions, which we call internal government. The sixth and seventh are overarching constraints which we call external government. They have been incorporated into the results-based M\&E model in Fig. 4 to reflect good governance in the public sector. Internal government requires the definition of good project organizational structure at the institutional level with identified individual responsibility for results, Fig. 3.

\section{Propositions}

Based on Figs. 1, 2, 3, 4, we have developed the following propositions:

P1: Strategy and objectives The realization of the best results from a project and their acceptance are increased by alignment of the project strategy to government strategy, and the clear definition of needs and project objectives. This is enhanced by effective start-up of the public project and the adoption of portfolio and program management. 


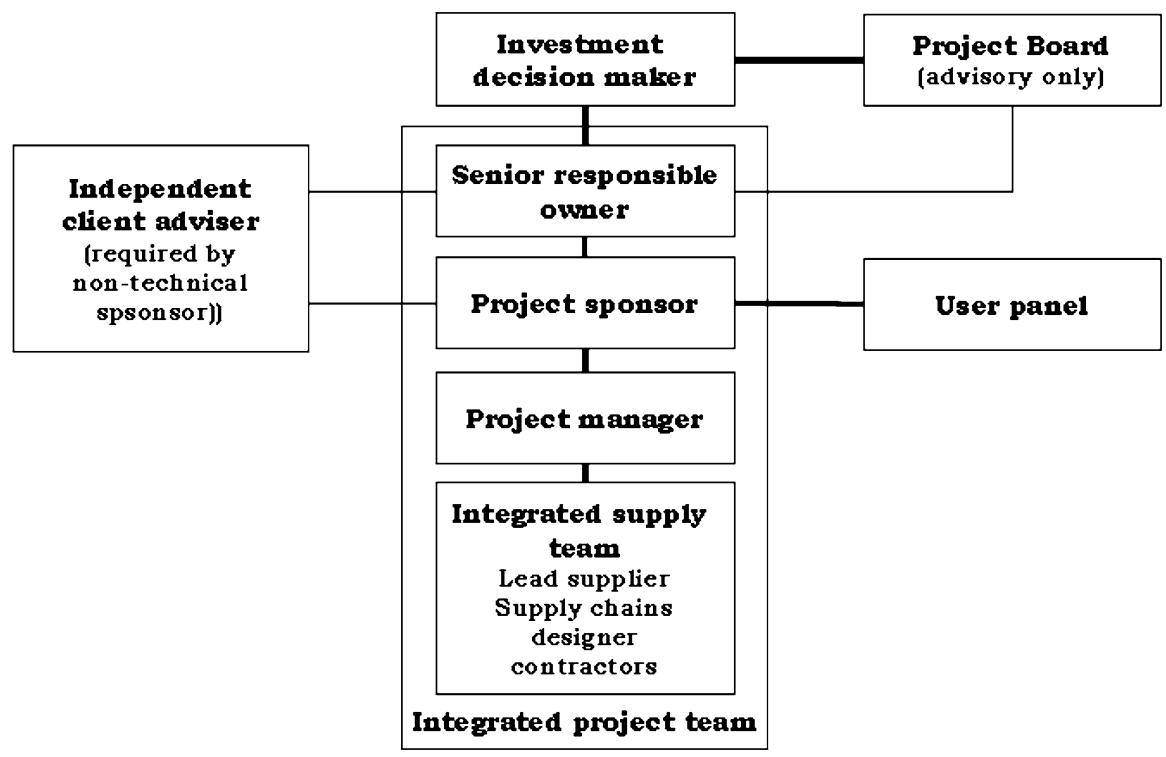

Fig. 4 Project organizational structure, with identified roles and responsibilities

P2: Conceptual planning and design The quality of the conceptual planning of the outputs, outcomes and impacts during the feasibility stage, as a basis for the detailed design, will increase the chance of obtaining best results. The plans (such as the business plan) are forecasts and not precise, but the logical relationship between the outputs and the outcomes and impacts help to align the outputs to their use, and the operation and maintenance of the new asset.

P3: Implementation Obtaining the best output is a necessary condition for achieving the best results; an insufficient output is a sufficient condition for not achieving the best results.

P4: Project transfer, operation and maintenance During initial operation, the results are improved by transferring the outputs and adapting the outcome based on experience of operation and maintenance. Maintenance and changes from this initial experience ensure fitness for long-term operation and the best impacts from the project.

P5: Project organization and individual Clear ownership of the project's results improves their attainment. This improvement is enhanced if the project organization clearly defines the owners and facilitates coordination among the relevant government departments, the investors and other third parties.

P6: Transparency and participation The interest, involvement and accountability of the project owner and the managers responsible for operation and maintenance improve the project results. This improvement will be enhanced if the 
operation and maintenance management has the appropriate influence during the project lifecycle.

P7: Monitoring and evaluation There is a positive relationship between M\&E activities of the control team and the probability of achieving the project objectives. A good condition for the effectiveness of monitoring and evaluation for the benefit is that the results of critical reports are distributed to the responsible parties, received well and lead to actions.

P8: Law, regulation and process The enforcement of the relevant laws and regulations and the political consensus are necessary for getting the acceptance for the public projects. A good condition is that professional processes are used for the projects.

P9: China public project context If the project results are coordinated with the context, and good governance principles are applied, the best results are more likely to be achieved.

\section{Methodology}

The results-based M\&E System was applied to analyze nine key infrastructure projects. A range of project types were studied and a variety of practical issues were identified and discussed during data collection. During this research, five of these projects were in operation, three were in the construction phase, at various stages of completion and the ninth was in design. The nine projects are shown in Table 2. Data were collected in several ways:

- access to project documents and project archival record

- interviews with the project owner, implementation agency and operators and users

- site visits

- observation of project meetings, including progress meetings and post project review

- workshops

- work groups within the Key Projects Inspectorate Office (KPIO)

- other sources such as World Bank and ADB specialists.

\section{Results}

Table 3 provides a summary of the extent to which the nine projects supported the nine propositions.

P1: Strategy and objectives There was strong support for this proposition. Eight of the case studies showed a strong link between government strategy and project objectives. For instance, the Yunnan Environmental Project clearly supported China's Environmental Action Plan and the World Bank's Development Strategy, and the Jiangsu Sutong Bridge was an important road link to improve economic 
Table 2 The nine case study projects

\begin{tabular}{llll}
\hline Project & Sector & Location & Stage \\
\hline Hebei Roads & Transportation & Hebei province & In operation for 3 years \\
$\begin{array}{l}\text { Yuannan Environment } \\
\text { Capital Museum }\end{array}$ & Urban environment & Yunnan province & In operation for 3 years \\
$\begin{array}{l}\text { Luanhuachi Xilu Roads } \\
\text { Sichuan Zipingpu Water }\end{array}$ & Culture & Beijing & In operation for 1 year \\
$\begin{array}{l}\text { Conservation } \\
\text { Beijing Youan Hospital }\end{array}$ & Water management & Sichuan province & In operation for 1 year \\
$\begin{array}{l}\text { Disabled Occupation and Skill } \\
\text { Sports Training Centre }\end{array}$ & Social welfare & Beijing & In construction \\
$\begin{array}{l}\text { Jiangsu Sutong Yangtze } \\
\text { River Highway Bridge }\end{array}$ & Transportation & Jiangsu province & In construction \\
$\begin{array}{l}\text { Guangxi Longtan Hydroelectric } \\
\text { Power Station }\end{array}$ & Energy & Buang & In construction \\
\hline
\end{tabular}

development on the north side of the Yangtze River. To be approved, projects had to fit into the multi-year strategy, purpose and planning. Where the objectives and indicators were not clear, it was on an intermediate level of detail and so related more to conceptual planning and design. Program and portfolio management help achieve good results, but they were not used on the Hebei Road Project which is why it only showed a moderate link.

P2: Conceptual planning and design There was strong support for this proposition. Positive and negative experiences clearly indicated that the quality of the conceptual planning of the outputs, outcomes and impacts contributes significantly to best results. In the Hebei Road Project, verifiable indicators were developed for outputs, outcomes and impacts. Economic development was an important impact, and that led to an adjustment in the design. On the Guangxi Longtan Hydroelectric Power Station, the feasibility study was comprehensive and the desired results were well defined. In several cases, conceptual planning had deficiencies, for example due to unrealistic assumptions. Problems arose in the later phases due to deficiencies in feasibility. With the Lianhuachi Xilu Road Project for instance, deficiencies in the feasibility study led to later problems with the cost estimate and time schedules. With the Beijing Capital Museum, the estimates of visitor numbers were very accurate, but weaknesses in the design of the operation meant targets were not set and success could not be judged in the post project evaluation. With the Sichuan Zipingpu Water Management Project, no farmers or irrigation experts were involved in the feasibility study, meaning one of the three important outcomes of the project was not properly delivered.

P3: Implementation and achieving project outputs There was moderate support for this proposition. Eight case studies showed the results-based M\&E System can contribute to project implementation and achievement of the output, but for six of those the support indication was only moderate. For instance in the Beijing Capital 
Table 3 Support for the nine propositions from the nine projects

\begin{tabular}{llllllllll}
\hline Project & P1 & P2 & P3 & P4 & P5 & P6 & P7 & P8 & P9 \\
\hline Hebei Roads & M & H & H & H & H & H & H & M & H \\
Yuannan Environment & H & H & M & M & H & M & H & M & H \\
Capital Museum & H & H & H & H & H & H & H & M & H \\
Luanhuachi Xilu Roads & H & H & M & M & H & H & M & H & M \\
Sichuan Zipingpu Water Cons & H & H & M & H & H & H & M & L & H \\
Beijing Youan Hospital & H & H & M & 0 & H & M & M & M & M \\
Disabled Occupation and Skill & H & M & L & 0 & M & M & M & M & H \\
$\quad$ Sports Training Centre & & & & & & & & & \\
Jiangsu Sutong Yangtze River & H & H & M & 0 & H & H & M & H & H \\
$\quad$ Highway Bridge & & & & & & & & & \\
Guangxi Longtan Hydroelectric & H & H & M & 0 & H & H & M & L & M \\
$\quad$ Power Station & & & & & & & & & \\
Totals & & & & & & & & & \\
H & 8 & 8 & 2 & 3 & 8 & 6 & 3 & 2 & 6 \\
M & 1 & 1 & 6 & 2 & 1 & 3 & 6 & 5 & 3 \\
L & 0 & 0 & 1 & 0 & 0 & 0 & 0 & 2 & 0 \\
0 & 0 & 0 & 0 & 4 & 0 & 0 & 0 & 0 & 0 \\
\hline
\end{tabular}

Key H: much support for the proposal, M: moderate support for the proposal, L: little support for the proposal, 0: not relevant

Museum the project deliverables were as expected and the project later won awards for the outcomes. On the other hand, the Beijing Disabled Centre in the end did not have adequate capacity, contradicting the finding. In large infrastructure projects, corrections of insufficient investments in later phases are only possible to a limited extent. With the output, a large part of the total result is determined. A potential for improvement would be a professional and overall project management which can focus on bridging the gap between strategy and detailed design and construction work. Several of the projects were delivered late. For instance with the Luanhuachi Xilu Roads Project, the construction time took twice the original plan, due in part to insufficient surveying and residents complaints about inadequate soundproofing both requiring rework.

P4: Project transfer, operation and maintenance There was moderate to strong support for this proposition from the five projects where it was relevant. They showed how the results-based M\&E system can support the transfer to operation and maintenance, but four were still in construction and design so gave no evidence. As a matter of course, the data for the long term was not available, and the effect of changing the facilities for a better fit and the maintenance in the long run could not be observed. For the facilities that were in operation, the short-time experience could be evaluated. Here, the cooperation with operations and maintenance and the handover and start-up of the operation contributed to the agreement. With the Hebei Road Project, the road operated as expected and the poverty reduction was achieved. With the Beijing Capital Museum, the project was transferred to operation in a 
well-prepared and coordinated way, and the ticket income is higher than expected. With the Luanhuachi Xilu Roads Project, it was not initially clear who should be the road operator, and because of the previously mentioned problems construction work continued into initial operation.

P5: Project organization and individual responsibility There was strong support for this proposition. The weakest aspect was the coordination between the public departments, but again, the results confirmed the importance of assigning individual responsibility and ownership. Although, insufficient coordination and unclear results ownership did not always lead to deficient outputs, they caused delays and unnecessary effort which is not a best result. The incentive systems would require more research; this aspect had too much detail for this research and was not observed and evaluated in detail. On the Yunnan Environmental Project, a steering committee was working with the provincial municipal governments and gave policy guidance in some areas. In those areas, positive results were achieved. Where roles were not well defined and coordination between agencies not facilitated, good results were not achieved. With the Lianhuachi Xilu Road Project, project management and ownership were not clear, and communication was poor, leading to some of the difficulties with the project. With the Sichuan Zipingpu Water Management Project, no responsibility was assigned for the irrigation and so although two of the three objectives of the project were very successfully achieved, the irrigation results were not.

P6: Transparency and participation Very strong evidence for the increase in transparency and participation was obtained through the selection of good projects, but there was both positive and negative evidence. Public participation and transparency are required for public projects, but can lead to complicated and slow decision making. However, the results show the value, especially for long-range infrastructure investments. With the Hebei Roads Project, considerable effort was put into stakeholder management and the views of local residents was taken into account in the design of access roads. With the Beijing Museum, there were several consultation meetings with local people leading to greater acceptance. With the Yunnan Environmental Project, many project indicators were suggested by foreign experts due to lack of knowledge amongst the local Chinese, but that led to a lack of acceptance of the project results and later problems. In the Beijing Youan Hospital, problems arose because the representatives of the users, the operation and maintenance, the investment management and hospital management were in different departments.

P7: Monitoring and evaluation There was moderate support for this proposition. There was generally wide acceptance of the M\&E system. The acceptance of the suggestion of installing the system and the mainly good results where an independent checking of the expected results was working, and less 'beauty writing' is taking place, lead to the view that the agreement would grow in the future. This could be checked with further research. On the Hebei Roads Project, the results-based M\&E system was used with positive results. With the Beijing Youan Hospital, the results-based M\&E system was used throughout and although the 
project was still in construction, the system was well received and was leading to reasonably positive results.

P8: Law, regulation and process This proposition had the weakest support, but it was still moderate. The enforcement of the relevant laws and regulations is normal for public projects. However, we found only moderate evidence, which is mainly due to the processes, including the government approval procedures and time management process. Project management standard processes were in operation in some projects only, so their effect, positive and negative, could not always be observed. In the Yunnan Environmental Project, the project was undertaken by government agencies reliant on central government support so they applied government policy. However, they had little experience with government tendering procedures. With the Jiangsu Sutong Bridge, safety regulations were important and strictly adhered to.

P9: China public project context We found strong support for this proposition. Due to the high interaction of the public projects with the context, its relevance was quite clear. The positive and negative evidences show that only the best practices plus the best fit to the project context can bring the value to the public project realization. Also the context itself (for example the application of methods from the market system) was changing in the last decades and is and will be, therefore, the context study is a continuous process. The Beijing Capital Museum was very prominent and visible to the public and the government supervised the project directly. With the Luanhuachi Xilu Road Project, the public bidding process led to lower prices than expected. Also landscaping was a significant part of the project and was awarded to local contractors.

The level of participation and quality of communications with the public are weaknesses which need to be resolved. Legally and logically the public should have the right information, be involved, present options and monitor project performance. This implies a higher level of social progress and a way to enhance confidence and trust between the public and the public sector. As the above will result in more information sharing, disclosure and transparency, under-the-table deals and corruption which existed and caused strong negative impact on the government's image could be reduced. The public is looking for real project results rather than activities and output. The M\&E system could be driven by the public, which can determine if the investment provides value for the money compared to other projects, so new benchmarks might be found to enhance projects performance. With input from the public, government decisions could be more cautious and wiser. Being open to the public could also limit the number of projects which are selected solely by one decision maker based on his/her views, and could limit the number of what people call 'image projects' whose purpose is not to resolve key problems but to demonstrate the decision maker's personal achievement in their careers, such as the many city squares in country areas which occupy farmers' land but are useless because few people like to visit them. The results-based M\&E system could demonstrate government's performance and accountability by evidence, and could enhance the public's understandings and trust of the government's strategy. 


\section{Analysis}

The aim of our study was to determine whether China can get the best results from key projects in the public sector by increasing the result orientation.

The first question was whether China can realize the maximum benefit from key projects in the public sector by increasing results orientation and performance. The answer is that the results of projects in the public sector in China can be improved through enhancing the results-oriented project management and governance. The best results do not depend on a few management system components, individuals and actions, but are achieved through a complex network of many factors which have to be managed in a reliable way over several years. If one important indicator is not sufficient, the best result is not achieved. Therefore, the hypotheses and information in this research are manifold and complex as illustrated in the previous section.

The result orientation in project management covers all phases of the project life cycle:

1. In the project identification and initiation stage: the alignment of the project to the strategy, well-defined needs and sound and clear project objectives are necessary as a basis for the best results

2. In the project feasibility, planning and design stage: there is a positive relationship among the quality of the conceptual planning of the outputs, outcomes and impacts, as a basis for the detailed design, and best results. The logic between the outputs and the outcomes and impacts help to align the outputs to the use, operation and maintenance

3. In the project implementation stage: the project output is a condition for the outcome and impact results of the project. The best output is a necessary condition to achieve those best results; an insufficient output is a sufficient condition to not achieve the best results

4. In the project transfer, operation and maintenance stage: during initial operation, the results are improved by transferring the outputs and adapting the outcome to the experience of the use, operation and maintenance. The maintenance and changes assure the fitness for the long run and the best impacts from the project.

Project results realization will be reduced if the results orientation is not implemented or not properly adopted in any stage of the life cycle. For large infrastructure projects (and probably other kinds of projects), the results-oriented project initiation and design have an even stronger effect on the public project results realization than the other phases.

The second question was whether a clear definition of the project organization, with the assignment of responsibility to project sponsors and owners, supported by sound public-sector governance, can improve benefits realization from key projects. Results-oriented public governance for achieving best project results include:

1. Project organization and individual responsibility: the clear ownership of the project improves results. Good conditions for this improvement are that the 
organization of the owners is well defined and coordinated and involves the relevant government departments, the investors and other third parties, that a steering committee that includes the project owners and the main operators and users supervises and improves the results of the project, and that an incentive system can support the results orientation.

2. Transparency and participation: the interest, involvement and accountability of the project owner and the operation and maintenance management improve the project results considerably. Transparent, useful and understandable internal and external information on the project about the actual and future stages enables the role keepers and various interested parties to take their responsibility.

3. Monitoring and evaluation: results-based M\&E improves the results of projects. There is a positive relationship between the M\&E activities of the control team and the probability of achieving the project objectives within the given context conditions. A good condition for the effectiveness of monitoring and evaluation is that the critical reports are distributed to the responsible parties, are received well and lead to actions.

4. Law, regulation and process: the enforcement of the relevant laws and regulations and the political consensus are necessary for getting the acceptance for public projects. A good condition is that professional processes are used for the projects.

Project results realization will be reduced, if the results-oriented governance elements are not used or not properly adopted in the project life cycle. In the present situation in China, the clear project ownership and the transparency and public participation have an even stronger effect on the public project result realization than other project governance components. If the project results are coordinated with the context, and the good governance principles and project management disciplines are applied, the best results are more likely to be achieved.

The feedback from the case studies (including the interviews with professionals working on key infrastructure projects in China) was very positive. The highest acceptance to achieve best results was given to the influence of the strategy and objectives, the conceptual planning and design and the project organization and individual components. The most effective project management factors for improving the present situation were:

- To manage the transfer from the strategy and objectives to the implementation with good work in the planning, design and procurement phase

- To prepare (with project activities) and realize the transfer from the outputs to the outcomes and inputs in the short- and long-term operation, maintenance and adaptation.

The feedback was not complete, perforce, for the cases that were in the construction phase, at the time of the field work; the real outcomes and impacts were still estimates. Also, the systems of the project monitoring, evaluation and governance were not yet implemented fully at the time of several case studies; the experience with these systems was limited. It takes time, effort and successful 
experiences for these systems to be strengthened, institutionalized and fully integrated into existing management systems (Mackay 2006; Schiavo-Campo 2005). Further contributions to the theory and practice are expected in the future due to the high relevance of the subject for the society and economy in general, and the public sector in particular.

The focus of the study is on results orientation rather than results-based supervision. The results-based supervision is using results achieved (and may be also expected results) as the basis for the monitoring and evaluation of the status and progress of the projects. The results orientation uses the realized and expected results as a key orientation for managing (and in particular for controlling) of the project, in such a way that the best results will be achieved. The core in the results orientation is the behaviour and attitude of the project organization and the involved individuals.

\section{Conclusions}

The Chinese economy has been growing rapidly over the last 30 years and public sector infrastructure projects have made significant contributions to that growth. However, there are weaknesses in the Chinese public sector which affect results realization of various investments. These problems can be solved by adopting results-oriented management of projects and programmes and by assigning clearer responsibilities to various stakeholders for results delivery and benefits realization. This article traced the development of public infrastructure project management in China and presented the findings of nine in-depth case studies of infrastructure projects in China. It proposed a model for benefits identification and realization through the project life cycle and the creation of a project organization with clear responsibilities for project owners, sponsors and other stakeholders for implementing the process and delivering the results to maximize benefits from key infrastructure projects. This approach can be generalized to apply to infrastructure projects in other emerging and transition economies.

Acknowledgments The research on which this study is based won the award of the IPMA Outstanding Research Contribution 2010, from the International Project Management Association in 2010.

\section{References}

Aberbach, J. D., \& Christensen, T. (2003). Translating modern ideas into theoretical state reform: Economics-inspired reforms and competing models of governance. Administration and Society, 35(5), 491-509.

Asian Development Bank. (2000). Promoting good governance: ADB's medium-term agenda and action plan. Manila, The Philippines: Asia Development Bank.

Asian Development Bank. (2006). Second governance and anticorruption action plan (GACAP II), Final Report. Manila, The Philippines: Asia Development Bank.

Australian National Audit Office. (2003). Better practice guide on public sector governance (Vol. 1 and 2). Canberra: Australian National Audit Office.

Barrett, P. (2003). Better practice public sector governance. Canberra: Australian National Audit Office. 
Binnendijk, A. (2000). Results-based management in the development co-operation agencies: A review of experience, background report. Paris, France: The Development Assistance Committee, Organization for Economic and Cooperative Development.

Bourgon, J. (2009). New directions in public administration, serving beyond the predictable. Public Policy and Administration, 24(3), 309-330.

Cameron, W. (2004). Public accountability: Effectiveness, equity, ethics. Australian Journal of Public Administration, 63(4), 59-67.

Cheng, C.-Y. (2007). China's new development plan: Strategy, agenda and prospects. Asian Affairs, 34(1), 47-60.

China National Audit Office. (2004). The auditing results on part of the national bonds financed urban infrastructure construction projects performance. Beijing: China National Audit Office.

Howard, C., \& Seth-Purdie, R. (2005). Governance issues for public sector boards. Australian Journal of Public Administration, 64(3), 56-68.

Huang, F., \& Lu, B. (2008). Research of the interrelation model of Chinese transportation and industry and commerce. In Proceedings of the 8th International Conference of Chinese Logistics and Transportation Professionals-Logistics; The Emerging Frontiers of Transportation and Development in China, 31 July to 3 August, 2008, Chengdu, China (pp. 376-382).

Kaufmann, D., Kraay, A., \& Mastruzzi, M. (2007). Governance matters VII: Aggregate and individual governance indicators, 1996-2007, Policy Research Working Paper 4654, World Bank, Washington, DC, USA.

Kulshreshta, P. (2008). Public sector governance reform, the World Bank's framework. International Journal of Public Sector Management, 31(5), 556-567.

Kusek, J. Z., \& Rist, R. C. (2004). Ten steps to a results-based monitoring and evaluation system: A handbook for development practitioners. Washington, DC: The World Bank.

Lockie, E., Campbell, B., \& Xue, Y. (2007). TA 4581-PRC: Developing a result-based national monitoring and evaluation system for key projects. China: World Bank and Asia Development Bank.

Mackay, K. (2006). Institutionalization of monitoring and evaluation systems to improve public sector management. International bank for reconstruction and development/The World Bank, Independent Evaluation Group \& The Thematic Group for Poverty Analysis, Monitoring and Impact Evaluation, Washington, DC, USA.

Office of Government Commerce. (2007). Managing successful programmes (2nd ed.). London: The Stationery Office.

Office of Government Commerce. (2009). Managing successful projects with PRINCE2 (2009th ed.). London: The Stationery Office.

Schiavo-Campo, S. (2005). Building country capacity for monitoring and evaluation in the public sector: Selected lessons of international experience. International Bank for Reconstruction and Development/The World Bank, Operations Evaluation Department, Washington, DC, USA.

Sheng, Y. K. (2008). What is good governance? Bangkok: United Nations Economic and Social Commission for Asia and the Pacific.

Tang, S., \& Lo, C. W. (2009). The political economy of service organization reform in China: An institutional choice analysis. Journal of Public Administration Research and Theory, 19, 731-767.

Turner, J. R. (2009). The handbook of project-based management (3rd ed.). New York: McGraw-Hill.

Turner, J. R., Huemann, M., Anbari, F. T., \& Bredillet, C. N. (2010). Perspectives on projects. New York: Routledge.

Van Wie Davis, E. (2009). Governance in China, 2010. Asian Affairs, 34(4), 195-211.

WK Kellogg Foundation. (2004). Logic model development guide. Battle Creek, MI: WK Kellogg Foundation.

World Bank. (2008). Development policy lending, World Bank operational manual, operational policies. International Bank for Reconstruction and Development/The World Bank, Development Data Group, Washington, DC, USA.

World Bank. (2010). Little data book. International Bank for Reconstruction and Development/The World Bank, Development Data Group, Washington, DC, USA.

Xue, Y. (2009). A results-based monitoring and evaluation system for key infrastructure projects. Unpublished Ph.D. Thesis, Lille School of Management, Lille, France.

Yao, S., \& Morgan, S. (2008). On the new economic policies promoted by the 17 th CCCP congress in China. World Economy, 30(9), 1129-1153. 